\title{
Existing plaques and neuritic abnormalities in APP:PSI mice are not affected by administration of the gamma-secretase inhibitor LY-4 I I 575
}

\author{
Monica Garcia-Alloza ${ }^{\dagger 1,2}$, Meenakshi Subramanian ${ }^{\dagger 1}$, Diana Thyssen ${ }^{1}$, \\ Laura A Borrelli1 ${ }^{1}$, Abdul Fauq ${ }^{2}$, Pritam Das ${ }^{3}$, Todd E Golde ${ }^{3}$, \\ Bradley T Hyman ${ }^{1}$ and Brian J Bacskai*1
}

\begin{abstract}
Address: ${ }^{1}$ MassGeneral Institute for Neurodegenerative Diseases, Massachusetts General Hospital, 114 16th Street, Charlestown, MA 02129, USA, ${ }^{2}$ Area de Fisiología, Facultad de Medicina, Universidad de Cádiz, Plaza de Falla 9. 11003 Cádiz, Spain and ${ }^{3}$ Department of Neuroscience, Mayo Clinic Jacksonville, Birdsall 210, 4500 San Pablo Rd, Jacksonville, FL 32224, USA

Email: Monica Garcia-Alloza - mogarcia3344@yahoo.es; Meenakshi Subramanian - psminakshi@gmail.com; Diana Thyssen - dianathyssen@gmail.com; Laura A Borrelli - laborrelli@partners.org; Abdul Fauq - fauq.abdul@mayo.edu; Pritam Das - das.pritam@mayo.edu; Todd E Golde - golde.todd@mayo.edu; Bradley T Hyman - bhyman@ partners.org; Brian J Bacskai* - bbacskai@partners.org

* Corresponding author †Equal contributors
\end{abstract}

Published: 6 May 2009

Molecular Neurodegeneration 2009, 4:19 doi:10.1186/1750-1326-4-19
Received: 30 March 2009

Accepted: 6 May 2009

This article is available from: http://www.molecularneurodegeneration.com/content/4/1/19

(C) 2009 Garcia-Alloza et al; licensee BioMed Central Ltd.

This is an Open Access article distributed under the terms of the Creative Commons Attribution License (http://creativecommons.org/licenses/by/2.0), which permits unrestricted use, distribution, and reproduction in any medium, provided the original work is properly cited.

\begin{abstract}
The $\gamma$-secretase complex is a major therapeutic target for the prevention and treatment of Alzheimer's disease. Previous studies have shown that treatment of young APP mice with specific inhibitors of $\gamma$-secretase prevented formation of new plaques. It has not yet been shown directly whether existing plaques would be affected by $\gamma$-secretase inhibitor treatment. Similarly, alterations in neuronal morphology in the immediate vicinity of plaques represent a plaque-specific neurotoxic effect. Reversal of these alterations is an important endpoint of successful therapy whether or not a treatment affects plaque size. In the present study we used longitudinal imaging in vivo with multiphoton microscopy to study the effects of the orally active $\gamma$-secretase inhibitor LY-4I I575 in I0-II month old APP:PSI mice with established amyloid pathology and neuritic abnormalities. Neurons expressed YFP allowing fluorescent detection of morphology whereas plaques were labelled with methoxy-XO4. The same identified neurites and plaques were followed in weekly imaging sessions in living mice treated daily $(5 \mathrm{mg} / \mathrm{kg})$ for 3 weeks with the compound. Although LY-4I I 575 reduced $A \beta$ levels in plasma and brain, it did not have an effect on the size of existing plaques. There was also no effect on the abnormal neuritic curvature near plaques, or the dystrophies in very close proximity to senile plaques. Our results suggest that therapeutics aimed at inhibition of $A \beta$ generation are less effective for reversal of existing plaques than for prevention of new plaque formation and have no effect on the plaque-mediated neuritic abnormalities, at least under these conditions where $A \beta$ production is suppressed but not completely blocked. Therefore, a combination therapy of $A \beta$ suppression with agents that increase clearance of amyloid and/or prevent neurotoxicity might be needed for a more effective treatment in patients with pre-existing pathology.
\end{abstract}




\section{Background}

Alzheimer's disease (AD) is the most common cause of dementia among elderly people and it has no known cure. Compelling evidence from histological and biochemical studies support the idea that the accumulation of amyloid- $\beta(A \beta)$ aggregates in the brain plays a seminal role in the pathogenesis of $\mathrm{AD}$ [1]. Likewise, the genetic evidence regarding familial mutations of the amyloid precursor protein (APP) and presenilins support the pathogenic role of $A \beta$ accumulation [2]. A $\beta$ deposits as compact or dense core plaques that are sources of focal neurotoxicity in transgenic mice and in $\mathrm{AD}$ [3]. In this regard, senile plaques are associated with neuritic dystrophies and synaptic loss [4-6] and it has also been shown that senile plaques may disrupt cortical synaptic integration[7].

$\mathrm{A} \beta$ is generated after sequential cleavage of APP by $\beta$ and $\gamma$-secretases. Therefore, both $\beta$-secretase [8] and $\gamma$-secretase inhibitors are primary pharmacological targets in the treatment of AD (for review see [9-11]). The $\gamma$-secretase complex is constituted by at least four integral membrane proteins including presenilin, nicastrin, APH-1 and PEN2. The activity of $\gamma$-secretase determines the solubility of the $A \beta$ fragments, with $A \beta 42$ more prone to aggregation than the shorter cleavage products [10]. Due to these considerations, different approaches towards modulating $\gamma$ secretase activity towards producing shorter peptide fragments are being developed. There has been considerable success in generating small molecules capable of entering the central nervous system that inhibit $\gamma$-secretase activity potently leading to a sustained reduction in brain $\mathrm{A} \beta$ levels [12]. In both humans and animal models, the use of $\gamma$ secretase inhibitors to reduce $A \beta$ levels and slow $A \beta$ deposition has been demonstrated. Administration of $\gamma$-secretase inhibitors significantly reduced $A \beta$ levels in plasma in control and AD patients [13,14], as well as in CSF [15]. Similarly, it has also been shown that inhibiting $\gamma$-secretase activity can reduce A $\beta$ levels in plasma, CSF and brain both in young and aged transgenic mice [16-18] and longterm treatments can slow senile plaque deposition in Tg2576 mice [19]. Moreover, acute treatment with $\gamma$-secretase inhibitors led to partial reversal of the deficits in hippocampal-dependent contextual fear conditioning test in Tg2576 mice [20]. The previous work has demonstrated positive effects of $\gamma$-secretase inhibition therapy to prevent or slow $A \beta$ progression. It is unknown, however, whether inhibiting $\gamma$-secretase activity will be effective in a treatment paradigm. Will inhibition of $\gamma$-secretase lead to the clearance of existing plaques or the reversal of the morphological alterations in neurons in the mouse models of $\mathrm{AD}$ ? In the present work, we use a well characterized $\gamma$ secretase inhibitor, N(2)-[(2S)-2-(3,5-difluorophenyl)-2hydroxyethanoyl]-N(1)-[(7S)-5-methyl-6-oxo-6,7-dihydro-5H-dibenzo[b,d]azepin-7-yl]-l-alaninamide (LY411575) [21,22] and multiphoton microscopy to assess in vivo the effect of long-term treatment on existing senile plaques and the neuronal abnormalities associated with the plaques in APPswe/PS1dE9 mice. This animal model shows early deposition of $A \beta$ by 4-6 months of age $[23,24]$ and develops neuritic dystrophies and abnormal neuritic curvature $[5,25]$. Therefore, at the age used in this study (10-11 months old) the $\mathrm{A} \beta$ deposition and related neuropathological changes represent a model of established neuropathology.

\section{Results}

In vivo effect of LY-4 I I 575 on size of existing plaques

The orally active $\gamma$-secretase inhibitor LY-411575 was administered daily via gavage for 3 weeks to APP:PS1 mice with pre-existing amyloid pathology. No adverse effects were observed in the mice during this treatment period. Using longitudinal imaging of the brain with multiphoton microscopy, the size of individual, identified plaques was monitored.

Mice were injected with methoxy-XO4 to label amyloid pathology and fluorescent angiograms were used to identify imaging volumes over time. With each plaque serving as its own control, as previously described [26], there was no significant effect of LY-411575 treatment on plaque

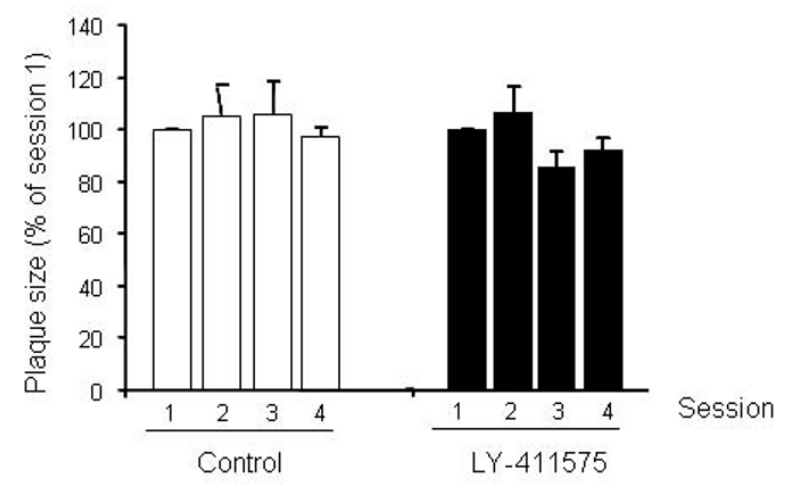

\section{Figure I}

LY-4 I I 575 treatment had no effect on the size of individual plaques in APPswe/PS I dE9xYFP mice. Individual, identified plaques were monitored with longitudinal imaging during the course of the treatment using multiphoton microscopy. Plaques in control treated animals did not change in size, as previously described $[25,26]$. Existing plaques in the treated mice were also unaffected; we did not detect a treatmentXsession effect $\left[F_{(3,218)}=1.087 ; P=0.356\right]$ or a treatment effect. However, there was a trend towards a slight reduction in plaque size at 2 weeks that was maintained until the end of the treatment. Data are representative of 16-57 plaques from 6-7 animals. 
size throughout the treatment period (Figure 1). This result suggests that prevention of amyloid production with potent secretase inhibitors has no effect on the size of existing plaques over a 3 week treatment protocol. It should be noted, however, that this may be a limitation of the dosage or treatment duration. Likewise, our measurements were based on using methoxy-XO4 as the plaque label, and this reports the congophilic core of plaques, not the halo of immuno-positive amyloid that tends to surround individual plaques. Hence, it is possible that very small or undetectable effects on plaque size may still lead to reduced neurotoxicity and beneficial effects.

\section{In vivo effect of LY-4 I I 575 on neuritic abnormalities}

It has been shown previously that neuritic processes in the vicinity of senile plaques are significantly more distorted, or "curvy", supporting the toxic effect of senile plaques and providing a useful model to study neuronal pathophysiology $[5,25]$. Using the quantitative curvature ratio, we have previously shown that these neuritic abnormalities can be at least partially reversed in short periods of time with candidate therapeutics $[5,6,27]$. We monitored these pathological abnormalities through the use of APPswe/PS1dE9 mice crossed with neuron specific YFP expression [28] to allow simultaneous multiphoton imaging of $A \beta$ deposits and neuronal processes throughout the treatment period. We examined the neurites located in the close proximity to senile plaques (within $50 \mu \mathrm{m}$ of plaque borders) where the distorted pathology is most severe. The average distance of the measured neurites to plaques before the beginning of the treatment for Control mice was $21.0 \pm 1.5 \mu \mathrm{m}(\mathrm{n}=66)$, and $24.1 \pm 1.2 \mu \mathrm{m}(\mathrm{n}=101)$ for LY-411575 treated mice. No statistical differences between average distances to plaques were detected using Student-t test $(\mathrm{P}=0.110)$. The stability of the selected population was also assessed in the consecutive sessions and no treatmentXsession effect was detected using two way ANOVA for repeated measures $\left(\left[\mathrm{F}_{(3,306)}=0.311 ; \mathrm{P}=\right.\right.$ 0.817] $\mathrm{n}=11-101$ from 3-4 mice), indicating that the selected neuritic populations were comparable. We did not observe any effect of the $\gamma$-secretase inhibitor LY411575 on the shaft diameter of the selected neurites (table 1). When we examined the morphology of the selected neurites, we observed a curvature ratio before starting the treatment (session 1, day 0) in the range previously described for this model $(\sim 0.955)[5,25]$ both for Control and LY-411575 groups. We did not detect a treatmentXsession effect using two-way ANOVA for repeated measures after 3 weeks of oral administration of LY411575 (Figure 2, Figure 3 for representative example).

We also monitored an additional neuritic alteration comprised of dystrophic swellings of neurites in the immediate vicinity of plaques. These dystrophies, which are thought to be dendritic as well as axonal [29], represent a
Table I: LY-4 I I575 has no effect on dystrophy size or neurite diameter in APPswe/PSIdE9xYFP mice

\begin{tabular}{lcccc}
\hline Treatment & \multicolumn{2}{l}{ Dystrophy size $\left(\mu \mathrm{m}^{2}\right)$} & \multicolumn{2}{l}{ Neurite diameter $(\mu \mathrm{m})$} \\
\hline & Control & LY-4I I575 & Control & LY-4 I I575 \\
\hline Session I & $5.4 \pm 0.7$ & $4.7 \pm 0.3$ & $0.95 \pm 0.04$ & $0.97 \pm 0.02$ \\
\hline Session 2 & $4.3 \pm 0.9$ & $5.5 \pm 0.5$ & $0.95 \pm 0.03$ & $1.07 \pm 0.05$ \\
\hline Session 3 & $6.3 \pm 0.9$ & $6.5 \pm 0.5$ & $1.00 \pm 0.04$ & $1.12 \pm 0.05$ \\
\hline Session 4 & $4.3 \pm 0.5$ & $6.2 \pm 0.5$ & $0.99 \pm 0.05$ & $1.12 \pm 0.06$ \\
\hline
\end{tabular}

LY-4II575 (5 mg/Kg) had no effect on dystrophy size when dystrophies located in close proximity to senile plaques (within 15 $\mu \mathrm{m}$ ) were measured in four consecutive imaging sessions using multiphoton imaging. The first imaging session (session I) was acquired before the commencement of the treatment. Animals received daily gavage administrations of LY-4II 575 or vehicle for 3 weeks. Imaging was performed on a weekly basis (sessions 2, 3 and 4). Analysis using a two way ANOVA for repeated measures resulted in: sessionXtreatment $\left.\left[F_{(3,1968)}=1.461 ; P=0.223\right]\right)$. Data are from 3-4 mice and 36-534 dystrophies. We also did not detect any significant effect on shaft diameter of the neurites, located within $50 \mu \mathrm{m}$ of plaques, (two way ANOVA for repeated measures sessionXtreatment $\left.\left[F_{(3,329)}=0.884 ; P=0.450\right]\right)$. Data are from 3-4 mice and 23-1II neurites.

distinct manifestation of plaque-specific neurotoxicity that can be at least partially reversed with candidate therapeutics $[27,30]$. When we assessed the size of these dystrophic swellings over time, we did not observe any effect after 3 weeks of treatment. Similarly, when we normalized the dystrophy size to plaque size we did not detect a significant sessionXtreatment effect $[\mathrm{F}(3,129)=0.428$; $\mathrm{P}=$ 0.734] (data not shown). These results demonstrate that this plaque associated neuronal pathology was not improved with treatment with the $\gamma$-secretase inhibitor. All together, these results suggest that even after 3 weeks of treatment, there was no detectable effect of $\gamma$-secretase inhibition on the neurotoxicity, manifested as morphological changes in neuronal processes, associated with existing plaques in vivo.

\section{Effect of LY-4 I I 575 on A $\beta 40$ and 42 levels in plasma}

Blood samples were taken at weekly intervals during the course of the study to monitor the effectiveness of $\gamma$-secretase inhibition. A standard ELISA kit was used to determine soluble $A \beta 40$ and 42 levels over time. Plasma levels of both $A \beta 40$ and 42 were significantly reduced in LY411575 treated mice within one week after the commencement of the treatment when compared to Control values, and this effect was maintained until the end of the treatment (Figure 4). This result demonstrates that the dose of inhibitor used was able to reduce circulating $A \beta$ levels by approximately $60 \%$ throughout the course of treatment. 


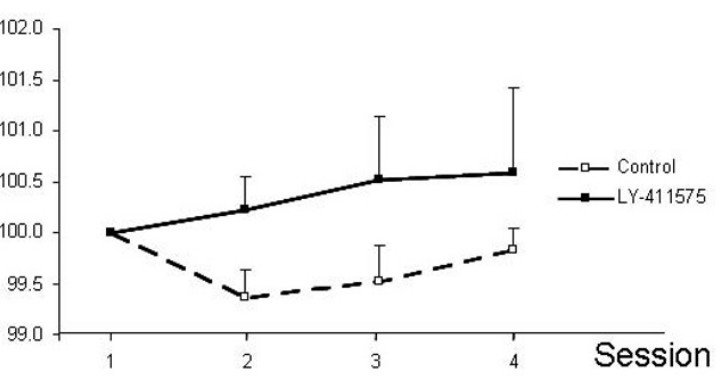

Figure 2

LY-4 I I 575 treatment had no effect on neuritic curvature in APPswe/PSIdE9xYFP mice when neurites up to $\mathbf{5 0} \mu \mathrm{m}$ from the plaque border were analyzed. Data are representative of 44-138 neurites from 8-9 animals. The first imaging session (session I) was acquired before the commencement of the treatment. Animals received daily gavage administrations of LY-4I I $575(5 \mathrm{mg}-\mathrm{Kg})$ or vehicle and for the next 3 weeks and imaging sessions were completed on a weekly basis (sessions 2, 3 and 4). The curvature ratio of the same identified neurites were measured over time, with each neurite serving as its own control. No treatmentXsession effect was detected $\left[F_{(3,561)}=0.171 ; P=0.916\right]$ despite a slight trend towards a straightening effect observed in LY4II575 mice at the conclusion of the treatment.

\section{Effect of LY-4 I I 575 on $A \beta 40$ and 42 levels in brain}

Biochemical measures of the effectiveness of the treatment were also used. At the end of the experiments, mice were killed, the brains extracted, and one hemisphere was flash frozen. These samples were homogenized and analyzed for $A \beta$ levels using standardized ELISA kits. The levels of soluble $A \beta 40$ and 42 in the brain were significantly reduced at the end of the treatment when compared to control values (Figure 5), supporting previous studies where similar effects were reported in a different mouse model [22]. The levels of formic acid extractable (insoluble) A $\beta 40$ and 42 were also reduced, but to a lesser extent. These results demonstrate that LY-411575 can reduce total $A \beta$ levels in the brain within this 3 week treatment period, in accord with previous reports.

\section{Discussion}

It is well established that exaggerated production and deposition of A $\beta$ aggregates as soluble oligomers, ADDLs, and senile plaques plays a key role in the pathogenesis of $\mathrm{AD}$ $[31,32]$. Therefore, blocking the production, limiting aggregation, or enhancing $A \beta$ clearance has become a major challenge in the treatment of the illness [33]. Concerted efforts have been directed towards the prevention of production of $A \beta$ through inhibition of $\gamma$-secretase. The
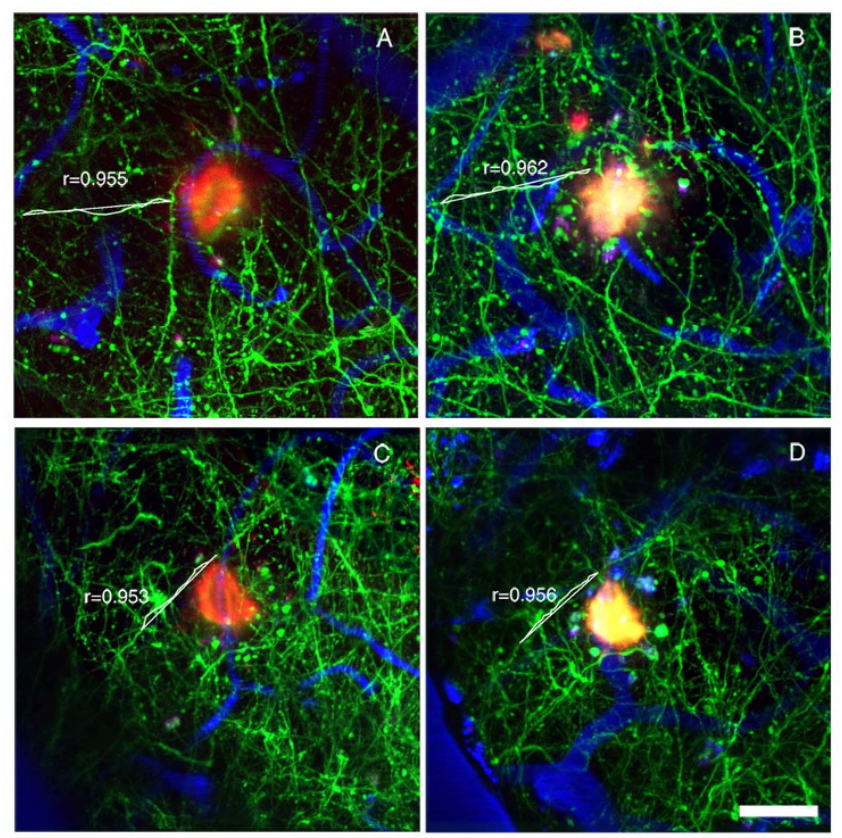

Figure 3

Representative example of the effect of LY-4 I I 575 treatment on neuritic curvature in APPswel PS I dE9xYFP mice. Animals received daily oral administration of LY-4I I $575(5 \mathrm{mg} / \mathrm{Kg})$ or vehicle for 3 weeks. These in vivo multiphoton images were taken before starting the treatment (session I, A-LY-4I I575, C-vehicle) and after 3 weeks of treatment (session 4, B-LY-4II 575 and D-vehicle). Each image is a maximum intensity projection of a small volume of the brain. Individual neurites are traced for the curvature measurements before and after treatment. Neurons are green, blood vessels are blue, and dense-core $A \beta$ plaques (red) were labeled by systemic injection of methoxy-XO4. Scale bar: $25 \mu \mathrm{m}$

$\gamma$-secretase is a multi-component protease complex that catalyzes the intramembranous cleavage of a number of type I tansmembrane proteins, including APP. Inhibiting APP processing reduces $A \beta$ production and this may prevent or limit the progression of the illness. Although an extensive bibliography supports the capacity of $\gamma$-secretase inhibitors to prevent $A \beta$ formation and aggregation both in human and in transgenic mouse models $[2,13,17,22]$, it remains unclear whether $\gamma$-secretase inhibition can also lead to reversal of existing pathology or the associated neuropathology. This distinction is important in the context of preventative vs treatment paradigms.

In the present work, we used as proof-in-principle the low molecular weight $\gamma$-secretase inhibitor LY-411575; a highly potent compound that crosses the blood-brain barrier and interacts with a binding site located in the PS1 Cterminal fragment [34]. It is well established that $\gamma$-secretase also leads to cleavage of other substrates, with Notch 

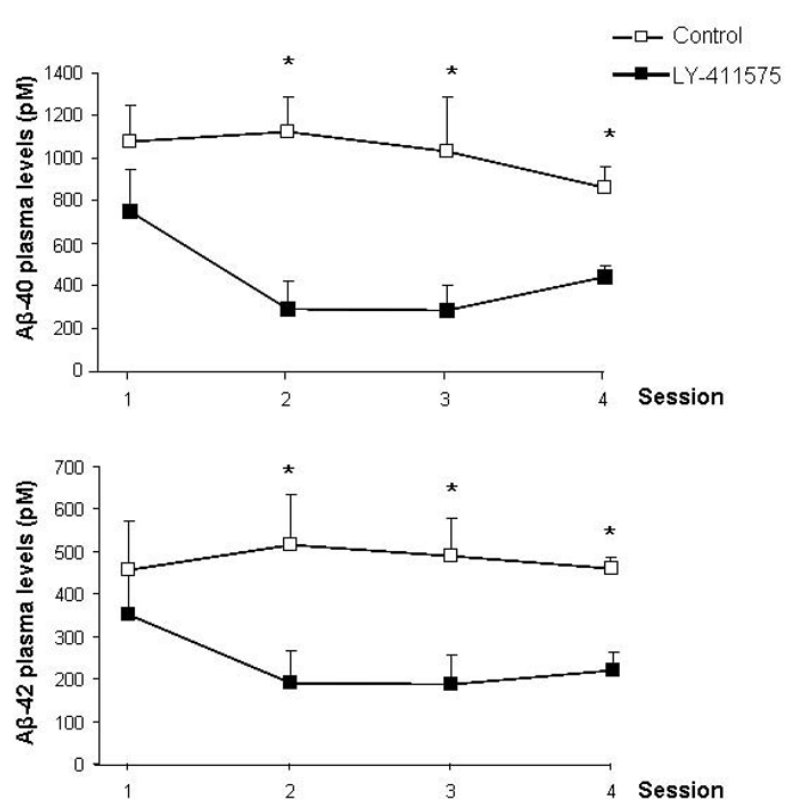

\section{Figure 4}

$L Y-4$ I I 575 treatment reduced $A \beta 40$ and 42 plasma levels in APPswe/PS IdE9xYFP mice. Animals received daily oral administration of LY-4I I575 $(5 \mathrm{mg} / \mathrm{Kg})$ or vehicle for 3 weeks. Plasma samples were taken before starting the treatment (session I) and on a weekly basis for the next 3 weeks. All measurements were done in duplicate and data are representative of 3-5 mice. We observed a significant sessionXtreatment effect $\left[\mathrm{F}_{(2,14)}=6.307 ; \mathrm{P}=0.0 \mathrm{II}\right]$ and $\left[F_{(2,14)}=1 \mathrm{I} .806 ; \mathrm{P}=0.00 \mathrm{I}\right]$ for $\mathrm{A} \beta 40$ and 42 respectively. Student-t test for independent sessions showed significant differences for both measurements after the first week of treatment when compared with control values. Differences were maintained until the end of the treatment $\left({ }^{*} p<0.05\right)$.

being an important alternative substrate. It has been reported, for example, that Notch inhibition induced by $\gamma$ secretase inhibitors can reduce thymus size and induce hyperplasia in the gastrointestinal track, however these side effects were reversible and can be controlled by adjusting dosage and length of the treatment [21]. Although we did not specifically check for adverse gastrointestinal and thymus effects, the dose used in this study ( $5 \mathrm{mg} / \mathrm{Kg} /$ day) did not induce the "sickly" phenotype described by Hyde et al [21] at higher doses.

We did, however, observe that chronic $\gamma$-secretase inhibition significantly reduced $A \beta 40$ and 42 plasma levels within 1 week after the commencement of the treatment. This effect confirms previous studies in other transgenic mouse models $[12,16,20,22,35]$ and in non transgenic mice [18]. Moreover, $\gamma$-secretase inhibitors have been shown to reduce $A \beta 40$ and 42 plasma levels both in healthy volunteers $[2,13]$ and in $\mathrm{AD}$ patients [14]. Similarly, when we assessed brain $A \beta 40$
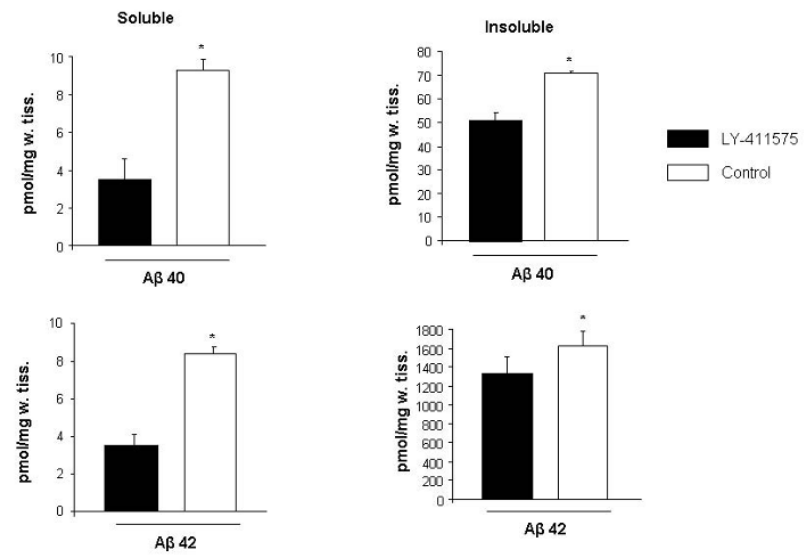

Figure 5

LY-4 I I 575 treatment reduced soluble and insoluble A 340 and 42 brain levels in APPswe/PSI dE9xYFP

mice. All measurements were done in triplicate and data are representative of 4-6 mice. Student-t test for independent samples showed a significant reduction of soluble and insoluble $A \beta 40$ and 42 brain levels after 3 weeks of treatment when compared with control values $\left({ }^{*} \mathrm{p}<0.05\right)$.

and A $\beta 42$ levels in APPswe/PS1dE9 mice we observed a significant effect after 3 weeks of treatment as previously shown with this compound in other transgenic mice [19,22,35]. All together, these data further support the capacity of LY411575 to cross the blood-brain barrier and reduce $A \beta$ levels both centrally and systemically. However, when we assessed the effect of LY-411575 on existing senile plaques we observed no reduction of plaque size after 3 weeks of treatment. Identified plaques were neither cleared, nor reduced in size. Several studies using cross-sectional analysis of tissue after chronic treatment of APP mice with $\gamma$-secretase inhibitors have demonstrated a reduction in plaque burden that probably reflects prevention of new plaque formation with no effect on plaque sizes $[19,36,37]$. These data support the idea that $\gamma$-secretase inhibition limits the production of new $\mathrm{A} \beta$ and therefore reduces the number of new senile plaques deposited without a major effect on the plaques already formed. Together, these data suggest that although $\gamma$-secretase inhibition can successfully reduce $\mathrm{A} \beta$ production and aggregation these compounds have a limited effect on reversing or clearing $A \beta$ deposits. These data are in accord with experiments performed in a mouse model with inducible APP expression. Nearly complete suppression of the transgene with doxycycline for an additional 6 months after plaque formation still revealed significant amyloid pathology in the brain, suggesting that established plaques do not spontaneously resolve even in the absence of continued $A \beta$ production [38].

There is compelling evidence associating compact senile plaques with synaptic loss and neuritic dystrophy forma- 
tion $[6,30]$. Senile plaques also seem to be responsible for the abnormal curvature of the surrounding neurites $[4,5,39]$, disruption of cortical synaptic integration [7] and abnormal calcium regulation in close proximity to senile plaques [40]. It has also been shown that soluble $\mathrm{A} \beta$ can provoke cell death by a progressive degeneration that begins in neurites and axons[41]. Taking these considerations into account, we extended our in vivo observations to neuronal processes and we assessed the effect of LY-411575 on neuritic abnormalities using multiphoton microscopy. This approach allowed us to explore the possibility of reversing neuritic abnormalities that develop within close proximity of senile plaques. As there is no overt neuronal loss in these mouse models, the neuritic alterations reflect the first steps in neurodegeneration and are a quantifiable index of neuropathology. We observed no effect on the size of neuritic dystrophies closely associated with plaques. Previous studies have shown that these dystrophies can be reduced or eliminated after antibody treatment against $A \beta[30]$ or treatment with curcumin [27]. While the ultimate effect of these dystrophies in the brain is unknown, it is clear that they represent a pathological response to plaques and are not common in healthy tissue.

When we assessed the effect of LY-411575 on neuritic curvature, we observed no effect during the treatment. Neurites are more distorted or "curvy" in the immediate surround of senile plaques, and this curvature can be at least partially reversed with immunotherapy [6] or antioxidant treatment $[5,27]$. The lack of an effect on the curvature ratio suggests that inhibiting $\gamma$ secretase does not prevent the neurotoxicity of existing amyloid deposits. It is, however, possible that longer or more potent treatments could prove beneficial.

\section{Conclusion}

All together, our data suggest that the $\gamma$-secretase inhibitor LY-411575 can successfully reduce A $\beta$ plasma and brain levels in treated mice, but has no effect over a 3 week period on established amyloid deposits or the neuronal abnormalities associated with senile plaques. This demonstrates that therapeutics aimed at inhibition of $A \beta$ generation are less effective for reversal of existing plaques than for prevention of new plaque formation [19]. Given the relatively short treatment duration of our study, however, longer term studies are warranted to determine whether or not long-term $\gamma$-secretase inhibition can reverse the neuropathological abnormalities seen in Alzheimer's disease. Since the ultimate goal would be to restore cognitive impairments that may result from $A \beta$ deposition followed by the associated neurodegeneration, a combination therapy may be warranted. Suppression of $\mathrm{A} \beta$ generation along with other therapeutic approaches, including immunotherapy or antioxidant agents that increase clearance of amyloid and reduce the toxic effects of $\mathrm{A} \beta$ deposition, could provide a more successful approach to treat the illness.

\section{Methods \\ Animals}

Animals were crosses of APPswe/PS1dE9 mice [42] with the YFP expressing mice (thy-1:YFP line $\mathrm{H}^{+/}$- Tg mice [28]) 10-11 months old, obtained from Jackson Lab (Bar Harbor, Maine). All studies were conducted with approved protocols from the Massachusetts General Hospital Animal Care and Use Committee and in compliance with $\mathrm{NIH}$ guidelines for the use of experimental animals.

\section{Reagents}

Texas Red dextran 70,000 D was obtained from Molecular probes (Eugene, OR), methoxy-XO4 was a gift from Dr. Klunk (U. Pittsburgh). LY-411575 was synthesized as described [43], and tested for potency using cell based assays [44]. Common chemical reagents where obtained from Sigma (St. Louis, MO).

\section{In vivo treatment and multiphoton imaging}

The chronic treatment of APPswe/PS1dE9xYFP involved daily gavage administration of LY-411575 (5 mg/Kg) for 3 weeks. Control animals followed similar procedures but received vehicle instead of $\gamma$-secretase inhibitor treatment.

Cranial window surgeries were performed as previously described [45]. Briefly, animals were anesthetized using isoflurane or avertin, the skin and periosteum were removed and a 6-mm diameter craniotomy was performed, making the anterior end immediately anterior to Bregma and the posterior end just anterior to Lambda. Glass windows $(8 \mathrm{~mm})$ were installed and secured with dental cement. All animals received an i.p injection of methoxy-XO4 ( 2.5 mg/kg), a fluorescent compound that crosses the blood-brain barrier and binds amyloid plaques [46], the day before the surgery. To facilitate finding the same sites in the brain between sessions, Texas Red dextran $(70,000 \mathrm{Da}, 62.5 \mathrm{mg} / \mathrm{kg}$ in sterile PBS) was injected into a lateral tail vein to provide a fluorescent angiogram before every imaging session. As previously described [47] two-photon fluorescence was generated with $800 \mathrm{~nm}$ excitation from a mode-locked Ti:Sapphire laser (MaiTai, Spectra-Physics, Mountain View, CA mounted on a multiphoton imaging system (Bio-Rad 1024ES, Bio-Rad, Hercules, CA). A custom-built external detector containing three photomultiplier tubes (Hamamatsu Photonics, Bridgewater, NJ) collected emitted light in the range 380-480, 500-540 and 560-650 nm. 3-color images were acquired for plaques, neurites, and angiography simultaneously using a $20 \times$ objective $(\mathrm{NA}=0.95$, Olympus). In vivo images at low resolution $(615 \times 615$ $\mu \mathrm{m}$; z-step, $5 \mu \mathrm{m}$, depth, $\sim 200 \mu \mathrm{m}$ ) were acquired to pro- 
vide a map of the area, using the angiogram as a 3-D fiducial. LY-411575 treated animals were imaged before the commencement of the treatment (session 1, day 0) and reimaged on a weekly basis for the next 3 consecutive weeks (completing sessions 2, 3 and 4). Control treated animals followed the identical imaging schedule.

\section{Image processing}

Plaque size was measured using the blue fluorescence channel corresponding to methoxy-XO4 labelling. The maximum intensity projection images were thresholded, segmented, and measured using ImageJ software. The same identified plaques were measured from each imaging session such that each plaque served as its own control. The size of each plaque was normalized to $100 \%$ at day 0 and then all plaque measurements over time were averaged for summary statistics.

To analyze neurite abnormalities higher resolution, images were captured to identify single neurites and plaques (125 $\times$ $125 \mu \mathrm{m}$; z-step, $0.8 \mu \mathrm{m}$, depth, $20 \mu \mathrm{m}$ approximately). To exclude motion artifacts induced by heartbeat and breathing, image stacks were aligned using AutoDeblur software (AutoQuant). Images from the green channel (YFP neurites) were further processed with the blind 3D deconvolution function in AutoDeblur to remove background noise. 2D projections of stacks from the three channels were combined in Adobe Photoshop 7 (Adobe Systems). Stacks were used to measure plaque size, dystrophy size, neurite curvature and neurite diameter. Neuritic dystrophies, defined as the areas of swelling in the immediate surrounding of the senile plaques (up to $15 \mu \mathrm{m}$ from plaques border) [30,48] were outlined on the 2D projections and the areas (in $\mu \mathrm{m}^{2}$ ) were measured with Image-J software. We also measured as many neurites as we could confidently follow (that were at least 20 $\mu \mathrm{m}$ long) that were present and identifiable in each of the weekly imaging sessions. Thus, the curvature data represent longitudinal imaging with each neurite serving as its own control. The neurite curvature ratio was calculated by dividing the end-to-end distance of a neurite segment by the total length between the two segment ends as previously described $[4,6,39]$. Neurite shaft diameters were measured at each end and the midpoint of each segment to provide an average diameter along its length. To determine the effect of proximity to plaques, the average distance between the nearest methoxy-XO4 stained amyloid plaque and each neuritic segment was calculated using the average of the distance from the plaque edge to each end and the midpoint of the neuritic segment on the three-channel images, and only neurites located in the proximity of a senile plaque (within 50 $\mu \mathrm{m}$ from a plaque border) were included in the study.

\section{ELISA measurements}

A $\beta 40$ and 42 were quantified in plasma and brain samples using colorimetric human A-beta 40 and A-beta 42 ELISA kits (WAKO Chemicals USA) as previously described [49] with modifications. Plasma samples were obtained on a weekly basis from the saphenous vein at the end of each imaging session. Blood samples were collected in Eppendorf tubes treated with $10 \mu \mathrm{l}$ of EDTA $(10 \mathrm{mg} / \mathrm{ml})$ and centrifuged at $3500 \mathrm{rpm}$ for 7 minutes. Plasma was frozen at $-80 \mathrm{C}$ until the ELISA was run. At the end of the experiments the mice were killed, the brains hemisected and soluble and insoluble $A \beta 40$ and $A \beta 42$ were quantified in flash frozen homogenized hemibrains. For plasma ELISA, samples were diluted in phosphate buffer with $0.2 \%$ BSA, $0.4 \mathrm{M} \mathrm{NaCl}$, $0.076 \%$ CHAPS, and 2 mM Na2EDTA. Plasma samples were analyzed in duplicate. For brain tissue ELISA, hemibrains were homogenized for $45 \mathrm{~s}$ at speed 20 (BioSpec TissueTearor $^{\mathrm{TM}}$ ) in extraction buffer $(10 \mathrm{uL} / \mathrm{mg}$ brain mass) with protease inhibitor (Complete Protease Cocktail, Roche Diagnostics GmbH, Mannheim, Germany). Extraction buffer consisted of deionized water with $50 \mathrm{mM}$ Tris $\mathrm{HCl}, 2 \mathrm{mM}$ EDTA $2 \mathrm{Na}, 0.01 \%$ Methiolate $\mathrm{Na}, 400 \mathrm{mM} \mathrm{NaCl}$, and $1 \%$ BSA. One millilitre of each homogenized brain was centrifuged at 15,000 RPM for 5 minutes at $4^{\circ} \mathrm{C}$. The supernatant was removed (soluble $A \beta, 1: 10$ final dilution), and the pellet was diluted 1:8 and homogenized in 70\% formic acid (800 uL FA for a $100 \mathrm{mg}$ pellet) and centrifuged at 15,000 RPM for 5 minutes at $4^{\circ} \mathrm{C}$. Supernatant was removed again (insoluble $\mathrm{A} \beta$ ) and neutralized in Tris buffer with $\mathrm{pH}=11$ (1 $M$ Tris with $70 \%$ formic acid). The insoluble fraction was further diluted for $A \beta 42$ measurements. Brain samples were analyzed in triplicate. Standard curves for both plasma and brain tissue ELISAs were made using human $A \beta 40$ and $A \beta 42$ standards provided in the ELISA kit. Absorbance was measured with a Wallac Victor 21420 Multilabel Counter (PerkinElmer Life \& Analytical Sciences, Shelton, CT) and data were expressed as $\mathrm{pmol} / \mathrm{g}$ wet tissue.

\section{Statistical analysis}

To assess the dynamics of senile plaque size, neurite curvature, and plasma A $\beta$ levels, two-way ANOVA for repeated measures were used. Dystrophy size, neurite diameter and $A \beta$ brain levels were assessed with one-way ANOVA.

\section{Competing interests}

The authors declare that they have no competing interests.

\section{Authors' contributions}

$\mathrm{MS}$ and BJB designed the study. MS carried out the invivio imaging experiments. MG-A and DT analyzed the imaging data. LAB performed the ELISA measurements. AF, PD and TEG characterized and provided LY-411575. TEG and BTH gave critical advice. MG-A and BJB wrote the manuscript. All authors read and approved the final mansucript.

\section{Acknowledgements}

This work was supported by NIH AG020570, EB000768, AG08487,

AG02553I, and a fellowship from the AHA-Bugher Foundation and Ramon y Cajal contract (MG-A). 


\section{References}

I. Walsh DM, Selkoe DJ: Oligomers on the brain: the emerging role of soluble protein aggregates in neurodegeneration. Protein Pept Lett 2004, I I:21 3-228.

2. Siemers E, Skinner M, Dean RA, Gonzales C, Satterwhite J, Farlow M, Ness D, May PC: Safety, tolerability, and changes in amyloid beta concentrations after administration of a gamma-secretase inhibitor in volunteers. Clin Neuropharmacol 2005, 28: $126-132$.

3. Urbanc B, Cruz L, Le R, Sanders J, Ashe KH, Duff K, Stanley HE, Irizarry MC, Hyman BT: Neurotoxic effects of thioflavin S-positive amyloid deposits in transgenic mice and Alzheimer's disease. Proc Natl Acad Sci USA 2002, 99:13990-I3995.

4. D'Amore JD, Kajdasz ST, McLellan ME, Bacskai BJ, Stern EA, Hyman $B T$ : In vivo multiphoton imaging of a transgenic mouse model of Alzheimer disease reveals marked thioflavine-Sassociated alterations in neurite trajectories. J Neuropathol Exp Neurol 2003, 62:137-145.

5. Garcia-Alloza M, Dodwell SA, Meyer-Luehmann M, Hyman BT, Bacskai BJ: Plaque-derived oxidative stress mediates distorted neurite trajectories in the Alzheimer mouse model. J Neuropathol Exp Neurol 2006, 65:1082-1089.

6. Lombardo JA, Stern EA, McLellan ME, Kajdasz ST, Hickey GA, Bacskai BJ, Hyman BT: Amyloid-beta antibody treatment leads to rapid normalization of plaque-induced neuritic alterations. J Neurosci 2003, 23:10879-10883.

7. Stern EA, Bacskai BJ, Hickey GA, Attenello FJ, Lombardo JA, Hyman BT: Cortical synaptic integration in vivo is disrupted by amyloid-beta plaques. J Neurosci 2004, 24:4535-4540.

8. Citron M: Emerging Alzheimer's disease therapies: inhibition of beta-secretase. Neurobiol Aging 2002, 23:1017-1022.

9. Barten DM, Meredith JE Jr, Zaczek R, Houston JG, Albright CF: Gamma-secretase inhibitors for Alzheimer's disease: balancing efficacy and toxicity. Drugs R D 2006, 7:87-97.

10. Evin G, Sernee MF, Masters CL: Inhibition of gamma-secretase as a therapeutic intervention for Alzheimer's disease: prospects, limitations and strategies. CNS Drugs 2006, 20:35I-372.

II. Golde TE: Disease modifying therapy for AD? J Neurochem 2006, 99:689-707.

12. Dovey HF, John V, Anderson JP, Chen LZ, de Saint Andrieu P, Fang LY, Freedman SB, Folmer B, Goldbach E, Holsztynska EJ, et al.: Functional gamma-secretase inhibitors reduce beta-amyloid peptide levels in brain. J Neurochem 2001, 76:173-181.

13. Siemers ER, Dean RA, Friedrich S, Ferguson-Sells L, Gonzales C, Farlow MR, May PC: Safety, tolerability, and effects on plasma and cerebrospinal fluid amyloid-beta after inhibition of gammasecretase. Clin Neuropharmacol 2007, 30:3 I7-325.

14. Siemers ER, Quinn JF, Kaye J, Farlow MR, Porsteinsson A, Tariot P, Zoulnouni P, Galvin JE, Holtzman DM, Knopman DS, et al.: Effects of a gamma-secretase inhibitor in a randomized study of patients with Alzheimer disease. Neurology 2006, 66:602-604.

15. Bateman RJ, Siemers ER, Mawuenyega KG, Wen G, Browning KR, Sigurdson WC, Yarasheski KE, Friedrich SW, Demattos RB, May PC, et al.: A gamma-secretase inhibitor decreases amyloid-beta production in the central nervous system. Ann Neurol 2009 in press.

16. Lanz TA, Himes CS, Pallante G, Adams L, Yamazaki S, Amore B, Merchant KM: The gamma-secretase inhibitor $\mathbf{N}$-[N-(3,5-difluorophenacetyl)-L-alanyl]-S-phenylglycine t-butyl ester reduces A beta levels in vivo in plasma and cerebrospinal fluid in young (plaque-free) and aged (plaque-bearing) Tg2576 mice. J Pharmacol Exp Ther 2003, 305:864-87I.

17. May PC, Yang Z, Li W-Y, Hyslop PA, Siemers E, Boggs LN: Multicompartimental phamacodynamic assessment of the funcitional gamm-secreatse inhibitor LY45039 in PDAPP tansgenic mice and non-transgenic mice. Neurobiol Aging 2004, 25(Suppl 25):65.

18. Yohrling G], Felsenstein KM, Conway KA, Zupa-Fernandez A, Brenneman DE, Arnold HM: A comparative analysis of brain and plasma Abeta levels in eight common non-transgenic mouse strains: validation of a specific immunoassay for total rodent Abeta. Curr Alzheimer Res 2007, 4:297-303.

19. Best JD, Smith DW, Reilly MA, O'Donnell R, Lewis HD, Ellis S, Wilkie N, Rosahl TW, Laroque PA, Boussiquet-Leroux C, et al.: The novel gamma secretase inhibitor $\mathbf{N}$-[cis-4-[(4-chlorophenyl)sulfonyl]-4-(2,5-difluorophenyl)cyclohexyl]-I, I, I-trifluorometh- anesulfonamide (MRK-560) reduces amyloid plaque deposition without evidence of notch-related pathology in the Tg2576 mouse. J Pharmacol Exp Ther 2007, 320:552-558.

20. Comery TA, Martone RL, Aschmies S, Atchison KP, Diamantidis G, Gong X, Zhou H, Kreft AF, Pangalos MN, Sonnenberg-Reines J, et al.: Acute gamma-secretase inhibition improves contextual fear conditioning in the Tg2576 mouse model of Alzheimer's disease. J Neurosci 2005, 25:8898-8902.

21. Hyde LA, McHugh NA, Chen J, Zhang Q, Manfra D, Nomeir AA, Josien $\mathrm{H}$, Bara T, Clader JW, Zhang L, et al.: Studies to investigate the in vivo therapeutic window of the gamma-secretase inhibitor N2-[(2S)-2-(3,5-difluorophenyl)-2-hydroxyethanoyl]-NI[(7S)-5-methyl-6-oxo-6,7-dihydro-5H-dibenzo[b,d]azepin-7yl]-L-alaninamide (LY4I I,575) in the CRND8 mouse. J Pharmacol Exp Ther 2006, 319: I I33-I143.

22. Lanz TA, Hosley JD, Adams WJ, Merchant KM: Studies of Abeta pharmacodynamics in the brain, cerebrospinal fluid, and plasma in young (plaque-free) Tg2576 mice using the gamma-secretase inhibitor N2-[(2S)-2-(3,5-difluorophenyl)2-hydroxyethanoyl]-N I-[(7S)-5-methyl-6-oxo-6,7-dihydro5H-dibenzo[b,d]azepin-7-yl]-L-alaninamide (LY-4 I I 575). J Pharmacol Exp Ther 2004, 309:49-55.

23. Garcia-Alloza M, Robbins EM, Zhang-Nunes SX, Purcell SM, Betensky RA, Raju S, Prada C, Greenberg SM, Bacskai BJ, Frosch MP: Characterization of amyloid deposition in the APPswe/PSIdE9 mouse model of Alzheimer disease. Neurobiol Dis 2006, 24:516-524

24. Jankowsky JL, Fadale DJ, Anderson J, Xu GM, Gonzales V, Jenkins NA, Copeland NG, Lee MK, Younkin LH, Wagner SL, et al.: Mutant presenilins specifically elevate the levels of the 42 residue beta-amyloid peptide in vivo: evidence for augmentation of a 42-specific gamma secretase. Hum Mol Genet 2004, I3:159-170.

25. Meyer-Luehmann M, Spires-Jones TL, Prada C, Garcia-Alloza M, de Calignon A, Rozkalne A, Koenigsknecht-Talboo J, Holtzman DM, Bacskai BJ, Hyman BT: Rapid appearance and local toxicity of amyloid-beta plaques in a mouse model of Alzheimer's disease. Nature 2008, 45 I:720-724.

26. Christie RH, Bacskai BJ, Zipfel WR, Williams RM, Kajdasz ST, Webb WW, Hyman BT: Growth arrest of individual senile plaques in a model of Alzheimer's disease observed by in vivo multiphoton microscopy. J Neurosci 200I, 2 I:858-864.

27. Garcia-Alloza M, Borrelli LA, Rozkalne A, Hyman BT, Bacskai BJ: Curcumin labels amyloid pathology in vivo, disrupts existing plaques, and partially restores distorted neurites in an Alzheimer mouse model. J Neurochem 2007, I 02: I095-I I 04.

28. Feng G, Mellor RH, Bernstein M, Keller-Peck C, Nguyen QT, Wallace $M$, Nerbonne JM, Lichtman JW, Sanes JR: Imaging neuronal subsets in transgenic mice expressing multiple spectral variants of GFP. Neuron 2000, 28:4|-5I.

29. Brendza RP, O'Brien C, Simmons K, McKeel DW, Bales KR, Paul SM, Olney JW, Sanes JR, Holtzman DM: PDAPP; YFP double transgenic mice: a tool to study amyloid-beta associated changes in axonal, dendritic, and synaptic structures. J Comp Neurol 2003, 456:375-383.

30. Brendza RP, Bacskai BJ, Cirrito JR, Simmons KA, Skoch JM, Klunk WE, Mathis CA, Bales KR, Paul SM, Hyman BT, Holtzman DM: AntiAbeta antibody treatment promotes the rapid recovery of amyloid-associated neuritic dystrophy in PDAPP transgenic mice. J Clin Invest 2005, I I 5:428-433.

31. Hyman BT, Gomez-Isla T: The natural history of Alzheimer neurofibrillary tangles and amyloid deposits. Neurobiol Aging 1997, I 8:386-387. discussion 389-392

32. Selkoe DJ: Alzheimer's disease: a central role for amyloid. J Neuropathol Exp Neurol 1994, 53:438-447.

33. Citron M: Strategies for disease modification in Alzheimer's disease. Nat Rev Neurosci 2004, 5:677-685.

34. Czirr E, Leuchtenberger S, Dorner-Ciossek C, Schneider A, Jucker M, Koo EH, Pietrzik CU, Baumann K, Weggen S: Insensitivity to Abeta42-lowering nonsteroidal anti-inflammatory drugs and gamma-secretase inhibitors is common among aggressive presenilin-I mutations. J Biol Chem 2007, 282:24504-245I 3.

35. Wong GT, Manfra D, Poulet FM, Zhang Q, Josien H, Bara T, Engstrom L, Pinzon-Ortiz M, Fine JS, Lee HJ, et al.: Chronic treatment with the gamma-secretase inhibitor LY-4II,575 inhibits betaamyloid peptide production and alters lymphopoiesis and 
intestinal cell differentiation. I Biol Chem 2004, 279: 12876-12882

36. Abramowski D, Wiederhold KH, Furrer $U$, Jaton AL, Neuenschwan$\operatorname{der}$ A, Runser MJ, Danner S, Reichwald J, Ammaturo D, Staab D, et al.: Dynamics of Abeta turnover and deposition in different beta-amyloid precursor protein transgenic mouse models following gamma-secretase inhibition. J Pharmacol Exp Ther 2008, 327:4|| - 424 .

37. Ness DK, Boggs LN, Hepburn DL, Gitter B, Long GG, May PC, Piroozi KS, Schafer KA, Z Y: Reduced B-amyloid burden, increased C-99 concentrations and evaluation of neuropathology in the brains of PDAPP mice given LY450I39 dihydrate daily by gavage for $\mathbf{5}$ months. Neurobiol Aging 2004, 25(Suppl 2):S238-S239.

38. Jankowsky LL, Slunt HH, Gonzales V, Savonenko AV, Wen JC, Jenkins NA, Copeland NG, Younkin LH, Lester HA, Younkin SG, Borchelt DR: Persistent amyloidosis following suppression of Abeta production in a transgenic model of Alzheimer disease. PLoS Med 2005, 2:e355.

39. Knowles RB, Wyart C, Buldyrev SV, Cruz L, Urbanc B, Hasselmo ME, Stanley HE, Hyman BT: Plaque-induced neurite abnormalities: implications for disruption of neural networks in Alzheimer's disease. Proc Natl Acad Sci USA 1999, 96:5274-5279.

40. Kuchibhotla KV, Goldman ST, Lattarulo CR, Wu HY, Hyman BT, Bacskai B]: Abeta plaques lead to aberrant regulation of calcium homeostasis in vivo resulting in structural and functional disruption of neuronal networks. Neuron 2008, 59:2।4-225.

4I. Whalen BM, Selkoe DJ, Hartley DM: Small non-fibrillar assemblies of amyloid beta-protein bearing the Arctic mutation induce rapid neuritic degeneration. Neurobiol Dis 2005, 20:254-266

42. Jankowsky JL, Slunt HH, Ratovitski T, Jenkins NA, Copeland NG, Borchelt DR: Co-expression of multiple transgenes in mouse CNS: a comparison of strategies. Biomol Eng 200I, 17:157-165.

43. Fauq AH, Simpson K, Maharvi GM, Golde T, Das P: A multigram chemical synthesis of the gamma-secretase inhibitor LY4I I 575 and its diastereoisomers. Bioorg Med Chem Lett 2007, I 7:6392-6395.

44. Kukar T, Murphy MP, Eriksen JL, Sagi SA, Weggen S, Smith TE, Ladd $\mathrm{T}$, Khan MA, Kache R, Beard J, et al.: Diverse compounds mimic Alzheimer disease-causing mutations by augmenting Abeta42 production. Nat Med 2005, I I:545-550.

45. Skoch J, Hickey G, Kajdasz S, Hyman BT, Bacskai B]: In vivo Imaging of Amyloid- $\beta$ Deposits in Mouse Brain with Multiphoton Microscopy Humana Press: 2004.

46. Klunk WE, Bacskai BJ, Mathis CA, Kajdasz ST, McLellan ME, Frosch MP, Debnath ML, Holt DP, Wang Y, Hyman BT: Imaging Abeta plaques in living transgenic mice with multiphoton microscopy and methoxy-X04, a systemically administered Congo red derivative. J Neuropathol Exp Neurol 2002, 61:797-805.

47. Bacskai BJ, Kajdasz ST, Christie RH, Carter C, Games D, Seubert P, Schenk D, Hyman BT: Imaging of amyloid-beta deposits in brains of living mice permits direct observation of clearance of plaques with immunotherapy. Nat Med 200I, 7:369-372

48. Tsai J, Grutzendler J, Duff K, Gan WB: Fibrillar amyloid deposition leads to local synaptic abnormalities and breakage of neuronal branches. Nat Neurosci 2004, 7: I I8I-I I 83.

49. Kawarabayashi T, Younkin LH, Saido TC, Shoji M, Ashe KH, Younkin SG: Age-dependent changes in brain, CSF, and plasma amyloid (beta) protein in the Tg2576 transgenic mouse model of Alzheimer's disease. J Neurosci 200I, 21:372-381.
Publish with Bio Med Central and every scientist can read your work free of charge

"BioMed Central will be the most significant development for disseminating the results of biomedical research in our lifetime. "

Sir Paul Nurse, Cancer Research UK

Your research papers will be:

- available free of charge to the entire biomedical community

- peer reviewed and published immediately upon acceptance

- cited in PubMed and archived on PubMed Central

- yours - you keep the copyright
BioMedcentral 